\title{
Sol-Gel and Layer-by-Layer Coatings for Flame-Retardant Cotton Fabrics: Recent Advances
}

\author{
Giulio Malucelli (D) \\ Department of Applied Science and Technology and local INSTM Unit, Viale Teresa Michel 5, 15121 Alessandria, \\ Italy; giulio.malucelli@polito.it; Tel.: +39-0131-229369
}

Received: 4 March 2020; Accepted: 27 March 2020; Published: 1 April 2020

\begin{abstract}
Surface-engineered coatings for the fire protection of cotton are being increasing used thanks to the ease of application of the coatings and their effectiveness in preventing flame propagation and improving resistance to irradiative heat flux exposure. Two main approaches have been extensively investigated, namely sol-gel derived coatings and layer-by-layer assemblies. These approaches are both capable of providing treated fabrics with outstanding flame-retardant features. Notwithstanding, according to the composition of the sol-gel recipes and the type of deposited layers, it is possible to design multifunctional (for example hydrophobic and electrically conductive) treatments. This review aims at discussing recent advances with respect to both strategies, highlighting current limitations, open challenges, and possible advances.
\end{abstract}

Keywords: cotton; surface engineering; sol-gel; layer-by-layer; coatings; flame retardance; flame spread tests; forced-combustion tests; durability

\section{Introduction}

In general, the high flammability of fibers and fabrics significantly limits their exploitation in those sectors where fire-proofing is mandatory. In fact, if not properly modified, textile materials burn very easily when exposed to a flame or an irradiative heat flux; subsequent smoke generation can further cause severe issues because of toxicity.

In order to overcome this issue, in the early 1950s flame retardants (FRs), i.e., materials that are able to inhibit or at least slow down the propagation of a flame, were proposed. Nowadays, some of these are commercially available products with a high effectiveness according to the specific chemical and/or physical mechanisms that take place when FRs activate [1,2].

Generally speaking, flaming combustion is a "simple" oxidative reaction that occurs in the gas phase in the presence of oxygen (or air) supplied by the atmosphere surrounding the burning material. The degrading material generates combustible gaseous species mixed together with atmospheric oxygen, hence starting a combustion process which is self-sustained by the exothermicity of the flame (Figure 1).

The chemical composition and structure of the FRs play a key role in determining the way through which the FRs can be active in the condensed or gas phase; in addition, overall flame retardance is strictly related to the structure and morphology of the flame-retarded system, as well as to its thermal and fire behavior $[1,3,4]$.

For an effective flame-retardant action, all FRs should contain some specific elements in their chemical structure (namely halogens, boron, nitrogen, phosphorus, and silicon, alone or in combination), so that synergistic effects can be possibly exploited. For bulky polymers, FRs can be incorporated utilizing different techniques: in particular, melt compounding is very often exploited; in some other cases FRs can be covalently linked to the polymer by means of grafting or copolymerization reactions [5]. 


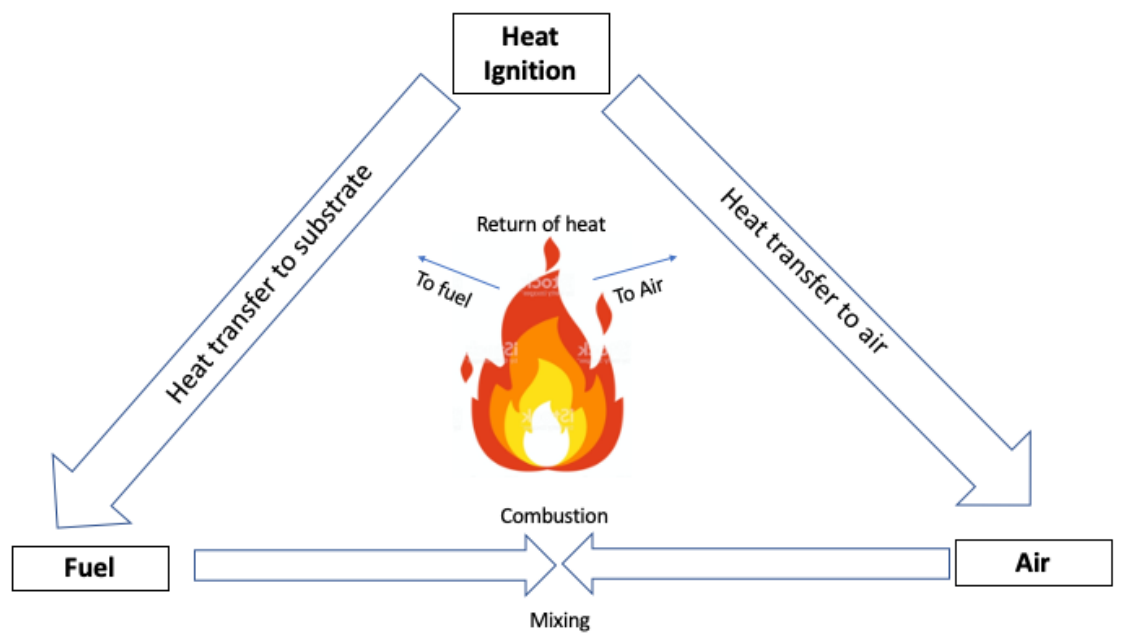

Figure 1. A self-sustaining combustion cycle (i.e., Emman's fire triangle) for flammable materials.

Conversely, textile materials show a very irregular surface; aside from some synthetic materials, which can be flame-retarded by incorporating specific additives into the polymer bulk before spinning, flame retardance is very often provided by using surface-engineered methods. In particular, the fibers and fabrics can be treated with solutions or suspensions (possibly waterborne, in order to avoid the use of toxic or environmentally unsound organic solvents) containing flame retardants. This way, it is possible to utilize the already available industrial impregnation/exhaustion lines. Then, specifically referring to fabric substrates, it is also possible to coat them with one or more flame-retardant layers (that can be continuous or not) on the side that will be exposed to the flame or the irradiative heat source alone, or on both sides. The optimization of the deposited layers allows for the best performance in fire $[6,7]$.

It is noteworthy that all these surface methods take advantage of the presence of flame retardants on the surface of the material for protection. In fact, the surface is the first to interact with the flame or the irradiative heat flux and therefore it is this, rather than the bulk, that has to be well protected.

Besides, the design of any flame retardant for textile materials has to fulfill the following conditions:

- The exothermicity of the reactions occurring during the interaction of the flame-retarded textile with the flame or heat source should be lower than that needed for maintaining the combustion process;

- Regarding the mechanism taking place in the condensed phase, the pyrolysis of the flame-retarded textile should promote a charring effect, limiting the production of combustible volatiles. This is unfavorable for continued combustion; in addition, it may be possible to exploit an intumescent effect provided by the flame-retarding treatment on the basis of the chemical structure and composition of the FR additive;

- The heat that is re-directed towards the textile should be restricted as much as possible: this way, it is possible to limit pyrolysis reactions that, in turn, may favor the formation of combustible volatiles;

- The FR treatment should not impact on the durability, softness of touch, dyeability, aesthetics, and even the external appearance of the treated fabrics.

From a technical point of view, some halogenated flame retardants (namely polychlorinated biphenyls and decabromodiphenyl or pentabromodiphenyl ethers) were found to be very efficient but at the same time toxic, and were therefore banned [8-11], hence pushing academic and industrial research towards the search for low-environmental-impact alternatives. In this context, phosphorus-based and/or phosphorus/nitrogen-containing additives were developed for the replacement of halogenated counterparts [12].

Specifically referring to the flame retardance of cotton, a good commercial halogen-free solution was identified thanks to the setup of flame retardants for coatings and back-coated fabrics or to the 
design and production of Proban ${ }^{\circledR}$ and Pyrovatex ${ }^{\circledR}$, which are based on hydroxymethylphosphonium salts and N-methylol phosphonopropionamide derivatives, respectively. These two latter derivatives show a high FR effectiveness, but also significant limitations. In particular, Pyrovatex ${ }^{\circledR}$ allows for linking almost $50 \%$ of the flame retardant to the fabric surface; therefore, the rest is lost during the first washing cycle. Regarding Proban ${ }^{\circledR}$, its application to the cellulosic textile requires a specific industrial plant process; in addition, formaldehyde may be released during the use of the flame-retarded material [13].

Though it is not easy to design and develop efficient and low-environmental-impact flame retardants, two surface engineering approaches have shown high potentialities, especially over the last 10 years: the first one is the sol-gel technique, a well-established method that appeared in the 1950s for synthesizing ceramic materials; the second is the layer-by-layer $(\mathrm{LbL})$ method, which appeared more recently than sol-gel as far as its application to fabrics is considered. Both approaches can be considered as effective ways to provide fabrics with multifunctional features, i.e., not only with flame-retardant properties, but also with hydrophobicity, antibacterial activity, and electrical conductivity, among other characteristics, depending on the chemical structure of the sol-gel precursors or of the deposited layer-by-layer (LbL) architectures [6,7].

From a general point of view, the sol-gel technique is very suitable for application to textiles, considering their irregular surface topography; besides, its industrial application can be carried out using already existing finishing lines. Furthermore, the high number of hydroxyl functionalities on the cellulosic substrate can be successfully utilized for covalently linking the sol-gel coating to the fabrics, hence improving their durability (i.e., resistance to washing treatments which textiles are very often subjected to).

The layer-by-layer (LbL) technique was discovered in the 1960s by Iler [14], who first proved the suitability of the process for assembling nanostructured layers through a molecularly-controlled method. Surprisingly, the LbL technique was abandoned until the early 1990s, when a useful methodology for producing nanoarchitectures consisting of layers of anionic and cationic polyelectrolytes on a substrate was proposed [15]. As a result, assembly deposited on fabrics does not affect their bulk mechanical behavior, providing, at the same time, useful features that are strictly dependent on the type and number of deposited layers [16-18].

This work aims at reviewing the current state-of-the-art and some possible future advances in the use of sol-gel and layer-by-layer methods for conferring flame-retardant features to cotton fabrics, the most commonly utilized natural textile material. Pros and cons will be highlighted as well, showing some step-forward advances that may allow for exploiting the two surface-engineered methods at a more efficient and larger scale.

\section{The Sol-Gel Approach Applied to Flame-Retardant Cotton Fabrics}

From an overall point of view, the sol-gel strategy exploits the use of reactive precursors, namely (semi)metal alkoxides, in hydrolysis and successive condensation reactions. In mild acidic conditions ( $\mathrm{pH}$ about 5-5.5), as schematized in Figure 2, the precursor is first partly hydrolyzed by water molecules. As a consequence, $\mathrm{M}-\mathrm{OH}$ groups (where $\mathrm{M}$ is a (semi)metal atom such as $\mathrm{Si}, \mathrm{Zn}$, or $\mathrm{Al}$,) are formed. Then, the latter undergo condensation reactions with other alkoxy groups (hence forming alcohols as by-products), or other hydroxyls groups (thus forming water as by-product). This way, according to the structure of the (semi)metal alkoxides, a fully inorganic or hybrid organic-inorganic 3D network is obtained. One of the main advantages of the sol-gel method refers to the possibility of carrying out the reactions at or near ambient temperature; however, in some cases, thermal treatments can be successfully employed for speeding up the kinetics of the involved reactions. In doing so, it is possible to decrease the overall time required for achieving $100 \%$ completion of the sol-gel process. The chemistry of this surface-engineered process involves the possible utilization of different (semi)metal alkoxides. Though the most commonly employed (semi)metal alkoxides usually include tetramethoxysilane (TMOS), tetraethoxysilane (TEOS), aluminum isopropoxide and titanium tetraisopropoxide, it is 
possible to widen the number of suitable precursors, including compounds containing organic groups (i.e., aliphatic or aromatic rings, saturated hydrocarbon chains, among others) and more complex structures bearing organic groups (such as aromatic or aliphatic rings, hydrocarbon units, ... ), hence giving rise to hybrid organic-inorganic 3D networks.

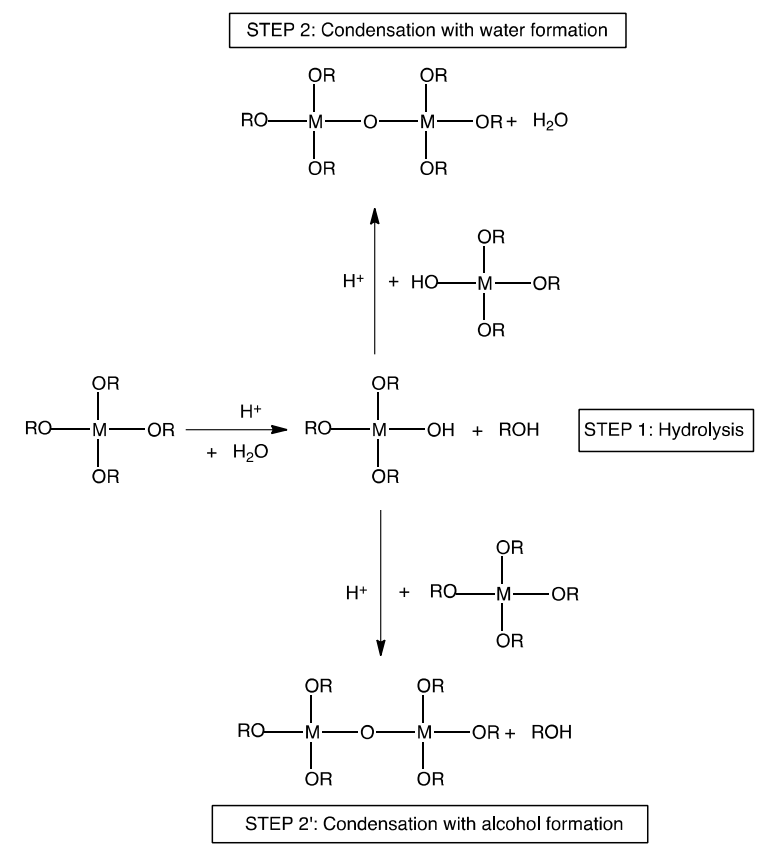

Figure 2. Schematic representation of sol-gel reactions taking place in acidic conditions $(\mathrm{M}=$ (semi)metal).

From a kinetics point of view, several parameters may affect the formation of the 3D structure: among them, of note are the chemical structure of the precursor(s), the precursor/water ratio, temperature, $\mathrm{pH}$, and possible addition of co-solvents (usually, ethanol, in order to dissolve the alkoxy precursors in water) to the sol formulation [19].

Though sol-gel coating treatments are capable of enhancing the flame retardance of the treated fabrics, the inadequate thickness of these latter may not be enough to provide the desired thermal shielding effect. As a consequence, sol-gel processes are often carried out combining the in situ-derived oxidic phases with other flame retardants. This way, it is possible to take advantage of at least joint or, in some cases, synergistic effects between the two components [20]. For this purpose, as described later, it is very usual to design sol-gel recipes containing nitrogen- and/or phosphorus- based FRs [21].

Furthermore, another "unconventional" approach exploits the combination (i.e., a dual-cure strategy) of a photoinduced polymerization with a subsequent thermal treatment in order to perform the sol-gel reactions: this way, it is possible to obtain hybrid organic-inorganic FR coatings, directly impregnating the textile with the liquid mixture containing both the organic monomers/oligomers and the alkoxy precursors [22].

The main features of the sol-gel approach performed on textiles are listed as follows:

- It is a chemical process that produces low-MW (molecular weight) molecules (such as water and alcohols) as by-products during the condensation reactions;

- As the method utilizes chemicals with high environmental impact, the overall environmental impact is high as well;

- Sol-gel treatments can be carried out by using the already available impregnation/exhaustion industrial plants; therefore, they are compatible with the existing textile finishing techniques, hence not requiring the design and construction of new apparatuses; 
- Softness to the touch is usually fair, though it can be ameliorated by using alkoxy precursors bearing long and flexible alkyl chains;

- Sol-gel treated fabrics are usually resistant to washing cycles, especially the cellulosic substrate, whose hydroxyl functionalities can be successfully exploited in condensation reactions for covalently linking the sol-gel coating to the underlying material;

- Depending on the structure and composition of the sol-gel precursors, it is often possible to design multifunctional coatings that exhibit not only flame-retardant features, but also other desirable properties.

In the next paragraph the advances related to sol-gel treatments performed on cotton are discussed. Specifically, the different resulting coatings will be divided into three groups, namely: fully inorganic, phosphorus-(nitrogen) doped, and hybrid organic-inorganic systems.

\subsection{Sol-Gel Fully Inorganic Coatings on Cotton}

These systems were the first to be applied to cotton in order to get acceptable flame-retardant properties: more specifically, TEOS was exploited as silica precursor, depositing a thin coating on the cellulosic substrate. The resulting ceramic layer turned out (1) to enhance the thermal stability of the fabric, as assessed in thermogravimetric analyses, and (2) to increase the time to ignition (TTI) and decrease the peak of the heat release rate (pkHRR), leaving a dense and coherent residue at the end of cone calorimetry tests.

As stated in the previous paragraph, the flame retardance of sol-gel derived coatings is strictly related to their structure, as well as to the experimental conditions selected for performing the hydrolysis and condensation reactions. Thus, it was necessary to thoroughly investigate the effects of different experimental parameters, namely temperature, time, structure of the alkoxy precursor, and precursor:water molar ratio [23]. The main outcomes of this work clearly indicated that the highest flame-retardant properties were achieved when TMOS was utilized as precursor, performing the sol-gel treatments at $80^{\circ} \mathrm{C}$ for $15 \mathrm{~h}$ and keeping a 1:1 water:TMOS molar ratio. Forced combustion tests revealed the effectiveness of the deposited silica coating in decreasing the peak of heat release rate (by about $15 \%$ ), hence confirming the thermal shielding effect provided by the ceramic layer that favored the dehydration of cotton, instead of the formation of volatile combustible gases, inducing, at the same time, the formation of a stable aromatic char [24].

Then, it was useful to study the effect of the type of hydrolysable groups on the overall flame retardant features of the cellulosic substrate: to this aim, three different precursors, namely TMOS, TEOS, and tetrabutylorthosilicate, bearing methoxy, ethoxy, and buthoxy groups, respectively, were utilized for designing sol-gel derived silica coatings [25]. Flame spread tests performed in vertical configuration revealed a clear effect of the type of alkoxy group employed for the formation of the silica coating, either on the residue at the end of the tests, or on the burning rate. More specifically, the best performances were obtained with TMOS (48 wt.\% final residue:), then TEOS (35 wt.\% final residue), and finally with tetrabutylorthosilicate (10 wt.\% final residue). A similar classification was found in cone calorimetry tests. In other words, the shorter the chain length of the precursor, the better the overall fire performance.

Following this research, the effect of the number of hydrolysable functionalities present in the alkoxy precursor was investigated: to this aim, the fire retardance provided by TEOS-derived coatings was compared with that from 3-aminopropyl trimethoxysilane (APTMS), triethoxy(ethyl)silane (TEES), 1,2-bis(triethoxysilyl)ethane (bTESE), diethoxy(methyl)phenylsilane (DEMPhS), and 1,4-bis(triethoxysilyl)benzene (bTESB) [25]. These compounds show different chemical structures because of the number of ethoxy functionalities (ranging from two for DEMPhS up to six for bTESB) or the presence of aromatic rings.

Several outcomes resulted by means of cone calorimetry tests. In particular: 
- When a limited number of hydrolysable groups (i.e., not exceeding 3) was present in the alkoxy precursor, the resulting thermal parameters were similar to TEOS, but with higher values of the smoke parameters. In addition, thin and inconsistent residues were obtained at the end of the cone calorimetry tests; conversely, coherent and thicker residues were found by substituting amino groups (APTMS) with alkyl chains (TEES).

- The utilization of bTESE in sol-gel formulations greatly increased cotton flammability; conversely, the use of bTESB prevented burning even after 10 flame applications (duration: $5 \mathrm{~s}$ each).

Pursuant to this research, the influence of the type of (semi)metal of the sol-gel precursor was investigated, comparing the flame-retardant features of silica coatings (derived from TEOS) with alumina, titania, or zirconia counterparts; the latter were sol-gel-derived from aluminum isopropylate, tetraethylortho-titanate or tetraethylortho-zirconate precursors, respectively [26]. Among the different ceramic systems, silica-based coatings showed the highest FR efficiency on cotton: in particular, forced-combustion tests performed on the treated fabrics highlighted about $56 \%$ increase of time to ignition, as well as a $20 \%$ decrease of peak of heat release rate with respect to the untreated textile. Besides, irrespective of lower FR performance, the highest abrasion resistance was observed when alumina and titania were sol-gel-synthesized on the fabrics.

On the basis of these promising results, it was then decided to further investigate the effect of the presence of alumina micro- or nano-particles embedded into sol-gel silica network. In fact, alumina is a well-known ceramic oxide that can improve the abrasion resistance of the materials when incorporated. Regardless of the size of the utilized $\mathrm{Al}_{2} \mathrm{O}_{3}$ particles, the treated cotton showed both increased fire behavior and abrasion resistance. Concerning the former, flame spread tests in horizontal configuration revealed a significant decrease of the total burning time (about $-45 \%$ ) for the silica-alumina treated fabrics, obtaining, at the same time, dense and coherent residues at the end of the tests [27].

\subsection{Sol-Gel Phosphorus-Doped Coatings on Cotton}

Sol-gel phosphorus-doped systems have been designed in order to provide the treated fabrics with high flame retardance by exploiting synergistic or at least joint effects occurring in the coating formed on the fabric [20]. More specifically, sol-gel recipes usually take advantage of the incorporation of phosphorus- or phosphorus/nitrogen-containing species [28-36].

There are three different possibilities for designing and obtaining sol-gel phosphorus-doped coatings: first, it is practicable to utilize alkoxy precursors bearing either phosphate or silane functionalities (i.e., employing an "all-in-one" starting product). Another possibility refers to the use of mixtures of alkoxysilane precursors with phosphoric acid sources. Lastly, it is possible to utilize phosphorus- and nitrogen-containing systems, which alkoxysilane precursors are incorporated into.

As a consequence of the sol-gel process, the resulting phosphorus-doped coatings exert a double function: first, they exhibit a thermal shielding effect when the treated cotton is exposed to an irradiative heat flux or to a flame; then, they favor the formation of a ceramic/carbonaceous residue resulting from the activation of the phosphoric acid source that, in turn, dehydrates the underlying cellulosic substrate (e.g., a charring effect).

Regarding the first strategy, the literature describes several examples. One of the pioneering papers reports on the use of diethylphosphatoethyltriethoxysilane (i.e., an alkoxysilane precursor incorporating phosphate groups) for the obtainment of flame-retardant hybrid P-Si organic/inorganic coatings on cotton. In particular, a multistep technique was applied, depositing 1-6 layers on the underlying substrate [28]. Cone calorimetry tests performed on the treated fabrics revealed a significant lowering of the combustion time (namely, around $-43 \%$ ): more specifically, flame out values were measured as 116 vs. 66,62 , and $80 \mathrm{~s}$ for pure cotton and the fabrics treated with 1, 3, and 6 layers, respectively. Furthermore, the deposited layers determined a reduction of total smoke release values that shifted from $26 \mathrm{~m}^{2} / \mathrm{m}^{2}$ (untreated cotton) to 20,15 , and $6 \mathrm{~m}^{2} / \mathrm{m}^{2}$ for the fabrics treated with 1 , 3 and 6 layers, respectively. These findings clearly demonstrated that the designed hybrid coatings possess good smoke-suppressant features. 
Pursuant to this research, a pre-hydrolysis stage performed on the alkoxy precursor allowed for further optimization of the designed hybrid coatings: in fact, it was possible to enhance the launderability of the treated fabrics, which were capable of tolerating up to five washing cycles carried out following the ISO 6330 standard [33].

Diethylphosphatoethyltriethoxysilane (DPTES) was then combined with 3-aminopropyl trimethoxysilane (APTMS), possibly in the presence of a melamine-based resin (MR, employed as $\mathrm{N}$-source), in order to assess possible synergisms taking place among the components of the sol-gel recipe [34]. The obtained coatings exhibited a high char-forming character, witnessed by the high residues (42 and $38 \mathrm{wt} . \%$ for APTMS/DPTES and APTMS/DPTES/MR treatments, respectively) at the end of thermogravimetric tests in air atmosphere.

The residues in air were further enhanced (achieving about $70 \mathrm{wt} . \%$ ) when MR was replaced with $\mathrm{N}, \mathrm{N}, \mathrm{N}^{\prime}, \mathrm{N}^{\prime}, \mathrm{N}^{\prime \prime}, \mathrm{N}^{\prime \prime}$-hexakis-methoxymethyl-[1,3,5] triazine-2,4,6-triamine [34]. Calculating Lewin's synergistic effectiveness parameter [20] allowed for demonstrating the occurrence of additive (in N-doped hybrid phosphorus-doped silica coatings) or synergistic (in hybrid P-doped silica coatings combined with 1-hydroxyethane 1,1-diphosphonic acid) effects.

Synergism was also proved by treating cotton with sol-gel silica coatings incorporating such phosphoric acid sources as $\mathrm{ZrP}$ nanoplatelets, aluminum phosphinate, or a mixture of aluminum phosphinate, melamine poly(phosphate) and zinc and boron oxide [29]. A remarkable increase of time to ignition (from 14 to $40 \mathrm{~s}$, for untreated and treated cotton fabrics, respectively) was observed in cone calorimetry tests. In addition, a high limiting oxygen index value (i.e., 30\%) was achieved for the fabrics treated with $5 \mathrm{wt} . \%$ of the phosphorus compounds in combination with the alkoxy precursor, with respect to the untreated cellulosic substrate (19\%).

Recently, cotton was sol-gel-treated with (3-trimethoxysilylpropyl)diethylenetriamine and phenylphosphonic acid, keeping the final dry add-on below $10 \mathrm{wt} . \%$ in order to prevent significant changes in the comfort softness to the touch) of the treated fabrics. Small-scale flame tests with surface and edge ignition, performed according to the EN ISO 15025 standard, showed self-extinguishing properties for the treated fabrics [37].

Then, a sol-gel precursor containing $\mathrm{P}, \mathrm{N}$, and $\mathrm{Si}$, namely (3-glycidyloxypropyl trimethoxysilane modified N-(phosphonomethyl) iminodiacetic acid (PGPTES), was co-hydrolyzed and co-condensated with TEOS, in order to obtain self-extinguishing cotton fabrics [38]. Apart from providing self-extinction, the doped silica coatings showed increased time to ignition and decreased heat release rate, peak of heat release rate and total heat release values, leaving a high residue $(26 \%)$ at the end of the forced-combustion tests.

Very recently, a P-containing siloxane compound, namely 2,2-dimethyl-1,3-propanediol( $3^{\prime}$-triethoxysilanepropyl)phosphoramidate, was synthesized and applied to cotton fabrics, exploiting the sol-gel approach. Flammability tests performed on the treated fabrics showed a remarkable increase of limiting oxygen index (from 18\% to $30.1 \%$ for the untreated and sol-gel treated cellulosic substrate, respectively); besides, as confirmed by vertical flame spread tests, the treated cotton achieved self-extinction: no afterflame and afterglow were observed and the char length at the end of the tests was below $15 \mathrm{~cm}$. In addition, the high char-forming character of the deposited sol-gel coating was confirmed by the high residue (i.e., $20 \%$ ) found at the end of cone calorimetry tests [39].

\subsection{Hybrid Organic-Inorganic Sol-Gel Coatings on Cotton}

As previously discussed, it is possible to provide cotton fabrics with flame-retardant features by designing hybrid organic-inorganic coatings through exploitation of the dual-cure process. More specifically, reactive monomers and/or oligomers are added to the sol, possibly in the presence of a coupling agent, i.e., a molecule that bears both alkoxy functionalities and reactive double bonds (usually acrylic or methacrylic groups). Thus, the coupling agent is able to react with both the organic monomers/oligomers and the alkoxy precursors. In doing so, a photo- or thermally-induced polymerization reaction that converts the organic monomers/oligomers is followed 
by a thermal treatment for the sol-gel reactions to occur. As a consequence, the formation of a hybrid organic-inorganic coating is obtained on the cellulosic substrate. This coating usually exhibits flexibility and washing fastness according to the structure of the organic monomers/oligomers employed; besides, the in-situ formed ceramic phases are responsible for an increased thermal stability, as well as for the flame-retardant features provided to the cellulosic substrate [40-42], which are not significantly affected by the presence of the organic part of the designed coatings.

A first pioneering work on cotton involved UV-curable acrylic formulations at different TMOS loadings (ranging from 30 to $80 \mathrm{wt} . \%$ ), in the presence of methacryloyloxypropyltrimethoxysilane (MEMO), utilized as a coupling agent. As a result, a co-continuous hybrid organic-inorganic 3D network was obtained [22]. Flammability tests performed in horizontal configuration on the fabrics treated with the sol containing $60 \mathrm{wt} . \%$ of TMOS in the sol recipe showed a decreased burning rate, as well as an increased residue at the end of the tests, though the samples did not reach self-extinction. Besides, as revealed by forced-combustion tests carried out at $35 \mathrm{~kW} / \mathrm{m}^{2}$ irradiative heat flux, the deposited hybrid coatings turned out to increase the time to ignition and the final residues as well, with respect to the untreated fabric.

Triglycidyl isocyanurate acrylate and tri(acryloyloxyethyl)phosphate were then selected as the main components of a dual-cure recipe applied to cotton [43]. Microscale combustion calorimetry tests showed decreased values of peak of heat release rate, heat release capacity and total heat of combustion for the treated fabrics.

Quite recently, specific hybrid organic-inorganic coatings were designed for providing cotton fabrics with superhydrophobicity and flame-retardant features [44]. To this aim, ammonium dihydrogen phosphate and/or guanidine carbonate were first incorporated into a sol-gel coating derived from aminopropyltriethoxysilane. Then, a polysiloxane or a fluorofunctional silane were employed as modifiers of the flame retardant formulation, hence providing the fabrics with superhydrophobic features. Synergism was found to occur between the components of the flame retardant formulation, leading to an outstanding increase of limiting oxygen index values (that approached $71 \%$ vs. $18 \%$, untreated cotton) and to a significant decrease $(-90 \%)$ of the maximum specific heat release rate, as assessed by microscale combustion calorimetry tests.

Sol-gel processes were also performed in the presence of aminopropyltriethoxysilane and phenylphosphonic dichloride for providing cotton fabrics with hybrid organic-inorganic FR coatings [45]. Vertical flame spread and microscale combustion calorimetry tests were utilized for assessing the fire retardance of the resulting treated fabrics. In particular, the sol-gel coatings allowed self-extinction: this finding was ascribed to the formation of a thermal insulating ceramic layer on the underlying cellulosic substrate.

Recently, the sol-gel method was exploited for conferring flame-retardant and superhydrophobic features to cotton fabrics [46]. To this aim, TEOS was mixed with a hydroxyl-terminated polydimethylsiloxane and ammonium polyphosphate. The resulting sol was applied to the fabrics using a dipping process, obtaining a polydimethylsiloxane-silica hybrid coating, with good adhesion to the underlying substrate, as proven by washing cycles. The treated fabrics achieved self-extinction in vertical flame spread tests, giving rise to the formation of a dense and coherent char; besides, the formation of polydimethylsiloxane moieties within the hybrid coating provided superhydrophobic features to cotton, as confirmed by the very high contact angle with water values (beyond $160^{\circ}$ ).

Very recently, TEOS was combined in a sol-gel recipe with phytic acid in order to combine the effect of the ceramic (silica phase) created by the alkoxy precursor with the char-forming character of phytic acid: its molecule, in fact, contains six phosphate groups that, upon exposure to a heat flux or a flame, decompose, giving rise to dehydration reactions on the cellulosic substrate, hence favoring the formation of char and limiting the generation of volatile combustible gases [47]. In particular, the treated fabrics with a total dry add-on of $16 \mathrm{wt} . \%$, together with a 70:30 TEOS:phytic acid weight ratio were self-extinguishing in vertical flame-spread tests. Besides, for this formulation, a significant reduction of heat release rate $(-36 \%)$, of the peak of heat release rate $(-74 \%)$, and of total heat release 
$(-39 \%)$ was observed in cone calorimetry tests, together with an important increase (about $+26 \%$ ) of the residue, which was dense and coherent at the end of the tests. However, the washing fastness of the sol-gel treated fabrics was quite limited, since they partially lost their flame-retardant features as a consequence of the partial removal of the deposited hybrid coatings.

A similar approach was recently proposed by Cheng and co-workers [48], who designed a hybrid sol-gel derived coating on cotton made of TEOS and phytic acid in the presence of sodium alginate. The deposited hybrid coating was found to improve the thermal stability of cotton, as revealed by thermogravimetric analyses. Besides, the treated fabrics, apart from being self-extinguishing in vertical flame spread tests, showed enhanced thermal and smoke parameters in cone calorimetry tests.

\section{The Layer-by-Layer (LbL) Approach Applied to Flame-Retardant Cotton Fabrics}

After 10-15 years of significant advances, the LbL method continues to be very well-known and effectively exploited by academic and industrial researchers, as it allows the combination of an almost limitless number of molecularly-sized components bearing different functionalities, permitting the design of tailored assemblies that, despite the very limited thickness, can confer peculiar properties to the underlying substrate without affecting its bulk characteristics [16-18].

Generally speaking, the layer-by-layer process takes advantage of the weak electrical charge already present on the substrate to coat, which is usually negative. Thus, the substrate is treated with diluted waterborne solutions or suspensions containing polyelectrolytes or micro- to nano-particles, respectively. A general scheme is presented in Figure 3. This way, it is possible to build up a nanostructured assembly, usually made of few (1 to 5 or 10) layers, though it is possible to deposit more that 50 layers. LbL assembly can exploit such techniques as dipping (the first that has been developed) or spraying: the latter is more suitable at a large (i.e, pilot/industrial) scale, while the former is generally employed for lab-scale treatments. The duration of each spraying or dipping step ranges from seconds to minutes, according to the selected experimental settings (such as $\mathrm{pH}$ [49,50], deposition temperature [51], ionic strength [52], possible rinsing and drying [53] in between two successive deposition steps, adsorption time [54], and type of selected substrate (plastics, metals, wood), among others), as well as to the kind of deposited layer $[55,56]$. In particular, rinsing and drying operations can be exploited for removing the excess of material deposited on the substrate (which may not adhere properly), and for prolonging the lifetime of the particles/polyelectrolyte baths by preventing possible contamination that takes place between the oppositely charged solutions/suspensions during each deposition step. As a result, it is possible to obtain assemblies bonded with electrostatic interactions by exploiting the surface reversal produced by the successive depositions of the layers.

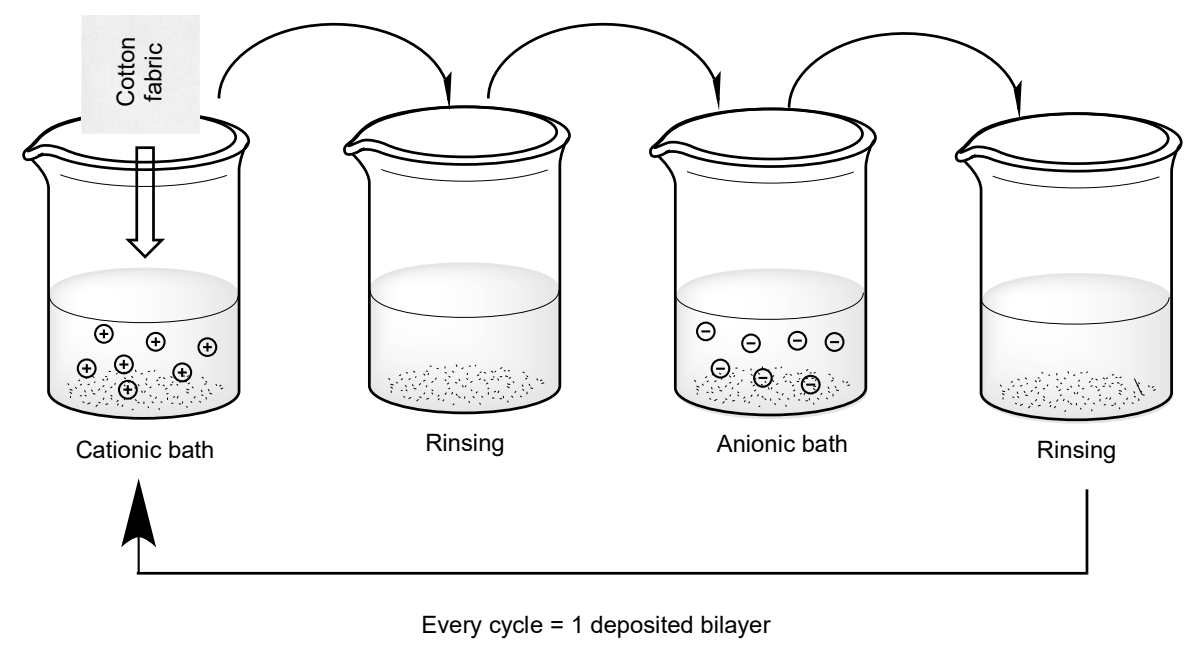

Figure 3. Scheme of the layer-by-layer (LbL) dipping process (first two depositions) carried out on a cotton fabric, using two polyelectrolytes/suspensions that are oppositely electrically charged. 
However, apart from electrostatic interactions, it is possible to utilize hydrogen $[57,58]$ or covalent [59,60] bonding, stereocomplex formation [61,62], or even donor/acceptor interactions [63].

As well described in the scientific literature, LbL constituents can be made of very different materials, comprising metallic or oxidic colloids [64-67], layered silicates [68-70], or cationic or anionic polyelectrolytes [71-73].

These LbL components can be combined according to their isoelectric point, which represents the $\mathrm{pH}$ at which the polyelectrolytes or the (nano)particles possess an equal number of positive and negative charges (i.e., zero net charge). Therefore, tuning the $\mathrm{pH}$ of the water solutions/dispersions allows for promoting a reversal of the electric charges, hence (1) widening the possibility of using the same layer constituents for the buildup of different assemblies on the underlying cellulosic substrate and (2) changing the thickness of the adsorbed layers [49,50].

With regard to flame retardance, the LbL method shows interesting peculiarities. First, depending on the composition of the deposited assemblies, it is possible to provide cotton fabrics with multifunctional features apart from fire resistance: in particular, the cellulosic substrate may become hydrophobic, electrically conductive, or even antibacterial. Then, the deposition is performed at room temperature and atmospheric pressure, i.e., in very mild conditions, using diluted (beneath $1 \mathrm{wt} . \%)$ and usually waterborne suspensions/solutions, thus limiting the environmental impact of the LbL treatments.

Next paragraphs will summarize the advances in flame retardance of cotton through LbL deposition over the last 10 years: in particular, the transition from fully inorganic to hybrid organic-inorganic and then to intumescent assemblies will be thoroughly discussed.

\subsection{Fully Inorganic LbL Assemblies on Cotton}

The first pioneering work dates back to 2011 and describes the performances of up to 20 bi-layered coatings of alumina-coated silica (positively charged; size: $10 \mathrm{~nm}$ ) and silica nanoparticles (negatively charged; size: 10 or $40 \mathrm{~nm}$ ), assembled on cotton. To this aim, dipping was exploited. Twenty bilayers provided the treated fabrics with self-extinction properties, as assessed in flame spread tests performed in vertical configuration; furthermore, the LbL assembly turned out to increase the time to ignition as observed in cone calorimetry tests [74].

The next step required the replacement of the dipping process with the spray-assisted method that was carried out either in a horizontal or vertical configuration, building up the same silica-based assemblies. It was found that horizontal spraying was more effective in covering the cellulosic substrate with a homogeneous and uniform coating as compared with the vertical process. As a result, the horizontally-sprayed assemblies showed the best behavior in forced-combustion tests, highlighting the efficacy of the ceramic assembly in lowering the total heat release and the peak of heat release rate, increasing, at the same time, the residue at the end of the tests $[75,76]$.

The possibility of exploiting the amphoteric behavior of alumina by tuning the $\mathrm{pH}$ of its aqueous dispersions allowed for replacing silica nanoparticles with $50 \mathrm{~nm}$ alumina nanoparticles that were oppositely electrically charged. The coatings assembled on cotton revealed an enhanced flame retardancy, together with improved tensile strength and UV transmittance [77].

Afterward, new fully inorganic layer-by-layer assemblies, based on Polyhedral Oligomeric Silsesquioxane (POSS ${ }^{\circledR}$ ) salts, were conceived and applied to cotton fabrics. First, bi-layered coatings made of water-soluble OctaTetramethylammonium POSS (negatively charged, (-)POSS) and OctaAmmonium POSS (positively charged, (+)POSS) were placed on the cellulosic substrate using a dipping process. Besides, OctaAmmonium POSS was also replaced with an aminopropyl silsesquioxane oligomer [78]. As assessed by pyrolysis combustion flow calorimetry tests, the coated fabrics displayed a significant char forming character, witnessed by the high final residue (12 wt.\%). In addition, flammability tests performed in vertical configuration showed decreased afterglow time and burning rate for the LbL-treated specimens; for the latter, at the end of the tests the texture and 
shape of individual fibers were preserved, hence indicating a good protective action exerted by the deposited bilayers on the underlying fabric.

\subsection{Intumescent LbL Assemblies on Cotton}

The potentialities offered by fully inorganic layer-by-layer assemblies have been further improved through the design of intumescent systems on cotton fabrics. This way, it is possible to exploit the thermal shielding effect exerted by the ceramic constituents with the char-forming features provided by the intumescent components in an "all-in-one" coating.

In particular, the first pioneering work describes the combination, with bi-layered assembly on cotton, of sodium phosphates (chosen as acid source) with poly(allylamine) (utilized as either a carbon source or blowing agent) [79]. For the LbL-treated fabrics, it was not possible to ignite the specimens under the cone calorimeter using a $35 \mathrm{~kW} / \mathrm{m}^{2}$ irradiative heat flux; besides, the surface engineered treatment provided the fabric with self-extinction properties, as proven by flammability tests carried out in vertical configuration.

Instead of using a bi-layered intumescent structure, more complex assemblies were designed on cotton fabrics by combining poly(diallydimethylammonium chloride)/poly(acrylic acid)/poly(diallydimethylammonium chloride)/ammonium polyphosphate in a quad-layer assembly. In particular, five quadlayers ensured self-extinction to the cellulosic substrate when flammability tests in horizontal configuration were performed [80].

Recently, intumescent LbL treatments were further investigated by designing new recipes comprising intumescent-like biomacromolecules or biomacromolecules combined with intumescent layers: this strategy has opened the pathway towards the development of low-environmental-impact LbL assemblies.

First, chitosan (carbon source) was coupled with phytic acid (performing as an acid source) in bi-layered architectures on cotton. Self-extinguishing fabrics in vertical flame spread tests were easily obtained by simply adjusting the $\mathrm{pH}$ of each dipping solution. In particular, two $\mathrm{pH}$ values were selected and investigated: $\mathrm{pH}=4$ allowed the assembly of thinner layers incorporating $66 \mathrm{wt} . \%$ of phytic acid, while working at $\mathrm{pH}=6$ allowed for obtaining thicker layers and with a lower acid source content (i.e., $48 \mathrm{wt} . \%)$. In all cases, the treated cotton achieved self-extinction in vertical flame spread tests [81].

Pursuing this research, chitosan and deoxyribonucleic acid (DNA) were coupled in bi-layered architectures in cotton: this is the first example of bio-sourced assembly, where an intumescent-like system, DNA, was successfully exploited in the formulation of a flame-retardant LbL coating [82]. Looking at its chemical structure, the biomacromolecule exhibits all the components of a typical intumescent system [83]. More specifically, DNA comprises deoxyribose units (behaving as a carbon source), together with phosphate groups (acid source) and nitrogen-containing bases (namely, adenine, guanine, cytosine, and thymine, acting as blowing agents). In horizontal flame spread tests, it was found that the assemblies made of 20 bilayers provided the treated cotton with self-extinction properties; besides, a very low burning rate was observed during flammability tests carried out in a horizontal configuration [84]. Finally, these assemblies allowed a decrease by $40 \%$ in the peak of the heat release rate in forced-combustion tests performed at $35 \mathrm{~kW} / \mathrm{m}^{2}$.

Quite recently, such chitin derivatives as chitosan (i.e., deacetylated chitin) and phosphorylated chitin were employed for obtaining another type of fully bio-based layer-by-layer assembly on cotton fabrics [85]. In particular, 20 bi-layered architectures provided the underlying textile with self-extinction properties, as assessed by vertical flame spread tests. The FR efficacy of the design treatments was also proven by the reduction of total heat release and peak of heat release rate as revealed by pyrolysis combustion flow calorimetry tests.

Coupling hypophosphorous acid-modified chitosan (negatively electrically charged) with polyethylenimine (positively charged) allowed for the design of specific LbL assemblies on cotton, showing not only good performance with respect to fire, but also an acceptable washing fastness [86]. 
This was possible to achieve by means of a cross-linking process with genipin, which is a water-soluble bifunctional crosslinking agent derived from gardenia fruits. The obtained assemblies turned out to favor the formation of a coherent and compact char, as revealed by the residues at the end of thermo-gravimetric analyses; furthermore, in horizontal flame spread tests, self-extinction was achieved by the fabrics treated with at least 10 bilayers. Finally, pyrolysis combustion flow calorimetry tests highlighted the capability of the designed LbL coatings to remarkably lower both the peak of heat release rate $(-73 \%)$ and total heat release $(-80 \%)$, with respect to the untreated fabrics.

\subsection{Hybrid Organic-Inorganic LbL Assemblies on Cotton}

Aiming at further widening the possible flame-retardant exploitation of the LbL method, inorganic layers have been coupled with organic molecules, hence giving rise to hybrid organic-inorganic assemblies on cotton. As a result, the thermal shielding provided by the inorganic layers can be successfully combined with the char-forming character of the organic counterparts, sometimes allowing synergistic effects to occur.

The first example of this type of coating assembled on cotton involves the preparation of hybrid assemblies made of poly(acrylic acid) and amino-functionalized montmorillonite nanoplatelets [87]. This combination was found to remarkably reduce the burning rate in flammability tests performed in a horizontal configuration; in addition, after burning, the formation of a swollen char near the amino-functionalized montmorillonite nanoplatelets proved the intumescent features of the designed assemblies.

Then, aiming at conferring not only flame retardance but also superhydrophobicity, a LbL dipping process was performed on cotton, combining, in a hybrid assembly, branched poly(ethylenimine), ammonium polyphosphate and a fluorinated silica@polydimethylsiloxane composite [88]. The LbL-treated cotton exhibited a high hydrophobicity, with static contact angle values with water of about $158^{\circ}$, hence showing high self-cleaning and antifouling properties. Besides, self-extinction was achieved for all the LbL-treated substrates, as assessed in vertical flame spread tests; in addition, the char-forming character of the deposited assemblies was proven by the creation of a coherent and compact residue, ascribed to asynergistic effect taking place between the inorganic and organic components of the hybrid coating. Finally, pyrolysis combustion flow calorimetry tests showed a significant decrease of both total heat release and peak of heat release rate for the treated fabrics with respect to the untreated counterpart.

Quite recently, polyethyleneimine was coupled with phosphorylated graphene oxides synthesized by a one-pot strategy and applied to cotton fabrics, giving rise to bi-layered assemblies; in particular, the effect of the graphene oxide phosphorylation on the fire behavior of 5 and 10 bi-layered coatings was thoroughly investigated, in comparison with the same assemblies containing the unmodified nanofiller [89]. It is noteworthy that the proposed hybrid organic-inorganic architecture also possesses intumescent features, as the phosphate groups present in the modified graphene oxide could be considered as acid sources, thus favoring the dehydration of the cellulosic substrate (i.e., the carbon source) toward the formation of a protective stable char. Then, the amino-groups of polyethyleneimine layers could act as blowing agents, helping the swelling of the intumescent system upon the exposure to a flame or an irradiative heat source. As assessed by SEM analyses, phosphorylated graphene oxide showed a better compatibility with water with respect to the unmodified nanofiller, hence giving rise to the formation of assemblies with a more homogeneous architecture on cotton and higher fire performances, as observed in vertical flame spread and forced-combustion tests.

Recently, hybrid organic-inorganic bi-layered architectures consisting of phytic acid and polyethyleneimine incorporating silica nanoparticles were applied to cotton using a dipping method [90]. The flammability of the resulting treated fabrics was assessed through limiting oxygen index (LOI) and vertical flame spread tests: a direct comparison between untreated cotton and its counterpart coated with seven bilayers revealed a remarkable increase of limiting oxygen index (18 vs. 33.7\%, respectively), as well as the self-extinguishing features for the treated samples. Besides, cone calorimetry tests 
highlighted the efficacy of the deposited assemblies in lowering the total heat release $(-52 \%)$ and peak of heat release rate (by about $75 \%$ ) of the fabric. Finally, it was noteworthy that the application of these hybrid coatings did not affect the overall mechanical behavior (i.e., softness to the touch) of the textile material.

Another recent work investigated the multifunctional character provided by phytic acid/polyethylenimine assemblies in the presence of silver nanowires; the latter were selected for obtaining electrically conductive networks on the surface of cotton [91]. In particular, the presence of $7.5 \mathrm{wt}$ \% of silver nanowires embedded in an assembly made of eight bilayers not only provided self-extinguishing features to the cellulosic substrate, but also conferred high electrical conductivity (about $2415 \mathrm{~S} / \mathrm{m}$ ) and electromagnetic interference shielding effectiveness (about $33 \mathrm{~dB}$ ). Further, in forced combustion tests, the peak of heat release rate was lowered by around $59 \%$ as compared with untreated cotton. Finally, all the described features were not affected by washing cycles or sandpaper abrasion tests, hence demonstrating a good durability of the proposed coatings.

$\mathrm{Li}$ and co-workers [92] recently exploited the LbL method for preparing hybrid quad-layered assemblies comprising polyethyleneimine, wrapped nanosilica, and polyphosphoric acid; besides, a water-repellent agent (REPELLAN FFTM) was finally coated on the treated cotton fabrics. This way, it was possible to provide the cellulosic substrate with hydrophobicity (the contact angle with water value was about $142^{\circ}$ ) and improved flame retardance. In particular, regarding the latter, the LbL-treated fabrics achieved self-extinction in vertical flame spread tests and showed high values of limiting oxygen index $(28.2 \%)$ as compared to untreated cotton $(18 \%)$

\section{Conclusions and Perspectives}

This review has undoubtedly demonstrated the advantages derived from the use of two well-established surface engineered strategies, i.e., the sol-gel and the layer-by-layer methods, for providing cotton fabrics with flame-retardant features. The improvements achievable by using flame retardant sol-gel coatings or layer-by-layer assemblies well support the developments these techniques are currently undergoing in the textile field. Besides, the opportunity of conferring multifunctional properties to cotton substrates, on the basis of either the sol-gel recipes or the LbL constituents, further broadens the potential utilization of the two surface engineered strategies, even for use at an industrial scale. However, some limitations that do not allow the full exploitation of sol-gel and LbL approaches are still being experienced.

As far as the sol-gel processes are considered, two main drawbacks have to be pointed out. First, as the sol-gel recipes currently involve chemicals, some of them with high environmental impact, the most recent research focuses on sol-gel precursors showing less impact on the environment. Also, depositing a ceramic or a hybrid organic-inorganic sol-gel derived coating on cotton may impact on the stiffness (i.e., softness to the touch) of the sol-gel treated fabric. In this context, especially for those applications (such as for wearable products) for which fabric comfort is required, the selection of "appropriate" sol-gel precursors incorporating aliphatic flexible chains may represent a solution for this issue, in combination with a tailored reduction of the dry add-on coating on the cellulosic substrate. In fact, in doing so, it is possible to minimize the thickness of the sol-gel coating, avoiding, at the same time, its accumulation within the fabric interstices.

Industrial-scale development represents the most important issue currently related to the layer-by-layer method. In fact, the dipping method is the most common, and standard LbL deposition is very repetitive and usually needs an extensive manual process. Conversely, spray-assisted LbL may represent the easiest scalable process for industrial exploitation, though only few attempts have been done so far to scale spray-assisted processes at a pre-industrial scale [93].

The weatherability/durability of the deposited assemblies is undoubtedly another limitation for greater exploitation of the method. As clearly described in the review, LbL assemblies are usually derived from waterborne systems: this means that, if not suitably covalently linked each other, the deposited layers are not able to withstand the washing cycles that cotton usually has to undergo 
during its utilization. The fire protection offered by the LbL assemblies is practically lost because of the removal of the layers during the laundry process. Some attempts have been carried out in order to resolve this issue. In particular, at the laboratory scale, the functionalization of the layer constituents with reactive groups has been successfully proposed. The latter can undergo a thermallyor photo-induced curing process [94,95], linking together the deposited layers.

Since durability is also related to the "overall stability" of the LbL architecture, which may be exposed to bacterial erosion or physical friction (among others), the covalent bonding of the layers to each other and to the underlying cotton substrate may significantly improve the weatherability of the designed assemblies. Besides, in dusty or humid circumstances the design of flame-retarded superhydrophobic assemblies may overcome durability issues.

Therefore, the potentialities of the sol-gel and LbL strategies for designing new, scalable, and cost-effective flame retardant architectures, together with the possibility of utilizing low environmental impact sol-gel precursors and LbL components, may substantiate their fast and growing expansion, hence giving rise to flame-retardant surface engineered solutions that will be ready for the market in the forthcoming years.

Funding: This research was funded by H2020 DAFIA Project (Biomacromolecules from municipal solid bio-waste fractions and fish waste for high added value applications, Grant no. 720770).

Conflicts of Interest: The author declares no conflict of interest.

\section{References}

1. Horrocks, A.R.; Price, D. Fire Retardant Materials; Woodhead Publishing Limited: Cambridge, UK, 2000.

2. Hilado, C.J. Flammability Handbook for Plastics, 5th ed.; CRC Press: Boca Raton, FL, USA, 1998.

3. Bourbigot, S. Flame Retardancy of Textiles-New Approaches; Woodhead Publishing: Cambridge, UK, 2008.

4. Weil, E.D.; Levchik, S.V. Flame retardants in commercial use or development for textiles. J. Fire Sci. 2008, 26, 243-281. [CrossRef]

5. Tsafack, M.J.; Levalois-Grützmacher, J. Plasma-induced graft-polymerization of flame retardant monomers onto PAN fabrics. Surf. Coat. Tech. 2006, 200, 3503-3510. [CrossRef]

6. Malucelli, G.; Carosio, F.; Alongi, J.; Fina, A.; Frache, A.; Camino, G. Materials engineering for surface-confined flame retardancy. Mat. Sci. Eng. R 2014, 84, 1-20. [CrossRef]

7. Alongi, J.; Carosio, F.; Malucelli, G. Current emerging techniques to impart flame retardancy to fabrics: An overview. Polym. Deg. Stab. 2014, 106, 138-149. [CrossRef]

8. Weijs, L.; Dirtu, A.C.; Malarvannan, G.; Covaci, A. Bioaccumulation and biotransformation of brominated flame retardants. Compre. Anal. Chem. 2015, 67, 433-491.

9. Howard, P.H.; Muir, D.C.G. Identifying new persistent and bioaccumulative organics among chemicals in commerce. Environ. Sci. Technol. 2010, 44, 2277-2285. [CrossRef]

10. Iqbal, M.; Syed, J.H.; Katsoyiannis, A.; Malik, R.N.; Farooqi, A.; Butt, A.; Li, J.; Zhang, G.; Cincinelli, A.; Jones, K.C. Legacy and emerging flame retardants (FRs) in the freshwater ecosystem: A review. Environ. Res. 2017, 152, 26-42. [CrossRef]

11. Hull, T.R.; Law, R.J. Environmental Drivers for Replacement of Halogenated Flame Retardants; Elsevier: Amsterdam, The Netherlands, 2014.

12. Horold, S. Phosphorus-Based and Intumescent Flame Retardants; Elsevier: Amsterdam, The Netherlands, 2014.

13. Muthu, S.S. Handbook of Sustainable Apparel Production; CRC Press: Boca Raton, FL, USA, 2015.

14. Iler, R.K. Multilayers of colloidal particles. J. Colloid Interf. Sci. 1996, 21, 569-594. [CrossRef]

15. Decher, G.; Hong, J.D. Buildup of Ultrathin Multilayer Films by a Self-assembly Process. 1. Consecutive Adsorprtion of Anionic and Cationic Bipolar Amphiphiles on Charged Surfaces. Makromol. Chem. Macromol. Symp. 1991, 46, 321-327. [CrossRef]

16. Richardson, J.J.; Björnmalm, M.; Caruso, F. Technology-driven layer-by-layer assembly of nanofilms. Science 2015, 348, aaa2491. [CrossRef]

17. Zhang, X.; Xu, Y.; Zhang, X.; Wu, H.; Shen, J.; Chen, R.; Xiong, Y.; Li, J.; Guo, S. Progress on the layer-by-layer assembly of multilayered polymer composites: Strategy, structural control and applications. Prog. Polym. Sci. 2019, 89, 76-107. [CrossRef] 
18. Richardson, J.J.; Cui, J.; Björnmalm, M.; Braunger, J.A.; Ejima, H.; Caruso, F. Innovation in layer-by-layer assembly. Chem. Rev. 2016, 116, 14828-14867. [CrossRef] [PubMed]

19. Alongi, J.; Malucelli, G. State of the art and perspectives on sol-gel derived hybrid architectures for flame retardancy of textiles. J. Mater. Chem. 2012, 22, 21805-21809. [CrossRef]

20. Lewin, M. Synergism and catalysis in flame retardancy of polymers. Polym. Adv. Tech. 2001, 12, $215-222$. [CrossRef]

21. Malucelli, G.; Rosace, G. Advances in Phosphorus-Based Flame Retardant Cotton Fabrics; Nova Science Publishers: New York, NY, USA, 2019.

22. Alongi, J.; Ciobanu, M.; Malucelli, G. Cotton fabrics treated with hybrid organic-inorganic coatings obtained through dual-cure processes. Cellulose 2011, 18, 1335-1348. [CrossRef]

23. Alongi, J.; Ciobanu, M.; Malucelli, G. Sol-gel treatments for enhancing flame retardancy and thermal stability of cotton fabrics: Optimization of the process and evaluation of durability. Cellulose 2011, 18, 167-177. [CrossRef]

24. Alongi, J.; Malucelli, G. Thermal Degradation of Cellulose and Cellulosic Substrates; Wiley: Hoboken, NJ, USA, 2015.

25. Alongi, J.; Ciobanu, M.; Malucelli, G. Sol-gel treatments on cotton fabrics for improving thermal and flame stability: Effect of the structure of the alkoxysilane precursor. Carbohydr. Polym. 2012, 87, 627-635. [CrossRef]

26. Alongi, J.; Ciobanu, M.; Malucelli, G. Thermal stability, flame retardancy and mechanical properties of cotton fabrics treated with inorganic coatings synthesized through sol-gel processes. Carbohydr. Polym. 2012, 87, 2093-2099. [CrossRef]

27. Alongi, J.; Malucelli, G. Thermal stability, flame retardancy and abrasion resistance of cotton and cotton-linen blends treated by sol-gel silica coatings containing alumina micro-or nano-particles. Polym. Degrad. Stab. 2013, 98, 1428-1438. [CrossRef]

28. Cireli, A.; Onar, N.; Ebeoglugil, M.F.; Kayatekin, I.; Kutlu, B.; Culha, O.; Celik, E. Development of flame retardancy properties of new halogen-free phosphorous doped $\mathrm{SiO}_{2}$ thin films on fabrics. J. Appl. Polym. Sci. 2007, 105, 3748-3756. [CrossRef]

29. Alongi, J.; Ciobanu, M.; Malucelli, G. Novel flame retardant finishing systems for cotton fabrics based on phosphorus-containing compounds and silica derived from sol-gel processes. Carbohydr. Polym. 2011, 85, 599-608. [CrossRef]

30. Yaman, N. Preparation and flammability properties of hybrid materials containing phosphorous compounds via sol-gel process. Fibers Polym. 2009, 10, 413-418. [CrossRef]

31. Bonnet, J.; Bounor-Legaré, V.; Boisson, F.; Melis, F.; Camino, G.; Cassagnau, P. Phosphorus based organic-inorganic hybrid materials prepared by reactive processing for EVA fire retardancy. Polym. Degrad. Stab. 2012, 97, 513-522. [CrossRef]

32. Alongi, J.; Colleoni, C.; Malucelli, G.; Rosace, G. Hybrid phosphorus-doped silica architectures derived from a multistep sol-gel process for improving thermal stability and flame retardancy of cotton fabrics. Polym. Degrad. Stab. 2012, 97, 1334-1344. [CrossRef]

33. Alongi, J.; Colleoni, C.; Rosace, G.; Malucelli, G. The role of pre-hydrolysis on multistep sol-gel processes for enhancing the flame retardancy of cotton. Cellulose 2013, 20, 525-535. [CrossRef]

34. Brancatelli, G.; Colleoni, C.; Massafra, M.R.; Rosace, G. Effect of hybrid phosphorus-doped silica thin films produced by sol-gel method on the thermal behavior of cotton fabrics. Polym. Degrad. Stab. 2011, 96, 483-490. [CrossRef]

35. Alongi, J.; Colleoni, C.; Rosace, G.; Malucelli, G. Thermal and fire stability of cotton fabrics coated with hybrid phosphorus-doped silica films. J. Therm. Anal. Calorim. 2012, 110, 1207-1216. [CrossRef]

36. Alongi, J.; Colleoni, C.; Rosace, G.; Malucelli, G. Phosphorus-and nitrogen-doped silica coatings for enhancing the flame retardancy of cotton: Synergisms or additive effects? Polym. Degrad. Stab. 2013, 98, 579-589. [CrossRef]

37. Kappes, R.S.; Urbainczyk, T.; Artz, U.; Textor, T.; Gutmann, J.S. Flame retardants based on amino silanes and phenylphosphonic acid. Polym. Degrad. Stab. 2016, 129, 168-179. [CrossRef]

38. Castellano, A.; Colleoni, C.; Iacono, G.; Mezzi, A.; Plutino, M.R.; Malucelli, G.; Rosace, G. Synthesis and characterization of a phosphorous/nitrogen based sol-gel coating as a novel halogen- and formaldehyde-free flame retardant finishing for cotton fabric. Polym. Degrad. Stab. 2019, 162, 148-159. [CrossRef] 
39. Jiang, Z.; Li, H.; He, Y.; Liu, Y.; Dong, C.; Zhu, P. Flame retardancy and thermal behavior of cotton fabrics based on a novel phosphorus-containing siloxane. Appl. Surf. Sci. 2019, 479, 765-775. [CrossRef]

40. Malucelli, G. Hybrid organic/inorganic coatings through dual-cure processes: State of the art and perspectives. Coatings 2016, 6, 10. [CrossRef]

41. Giamberini, M.; Malucelli, G. Hybrid organic-inorganic UV-cured films containing liquid-crystalline units. Thin Solid Film. 2013, 548, 150-156. [CrossRef]

42. Sangermano, M.; Amerio, E.; Malucelli, G. Hybrid organic-inorganic coatings obtained by cationic UV-Curing. Res. Signpost Kerala India 2010, 2, 149-161.

43. Xing, W.; Jie, G.; Song, L.; Hu, S.; Lv, X.; Wang, X. Flame retardancy and thermal degradation of cotton textiles based on UV-curable flame retardant coatings. Thermochim. Acta 2011, 513, 75-82. [CrossRef]

44. Przybylak, M.; Maciejewski, H.; Dutkiewicz, A.; Wesołek, D.; Władyka-Przybylak, M. Multifunctional, strongly hydrophobic and flame-retarded cotton fabrics modified with flame retardant agents and silicon compounds. Polym. Degrad. Stab. 2016, 128, 55-64. [CrossRef]

45. Liu, Y.; Pan, Y.T.; Wang, X.; Acuña, P.; Zhu, P.; Wagenknecht, U.; Heinrich, G.; Zhang, X.Q.; Wang, R.; Wang, D.-Y. Effect of phosphorus-containing inorganic-organic hybrid coating on the flammability of cotton fabrics: Synthesis, characterization and flammability. Chem. Eng. J. 2016, 294, 167-175. [CrossRef]

46. Lin, D.; Zeng, X.; Li, H.; Lai, X.; Wu, T. One-pot fabrication of superhydrophobic and flame-retardant coatings on cotton fabrics via sol-gel reaction. J. Colloid Interf. Sci. 2019, 533, 198-206. [CrossRef]

47. Barbalini, M.; Bertolla, L.; Toušek, J.; Malucelli, G. Hybrid silica-phytic acid coatings: Effect on the thermal stability and flame retardancy of cotton. Polymers 2019, 11, 1664. [CrossRef]

48. Cheng, X.-W.; Tang, R.-C.; Guan, J.-P.; Zhou, S.-Q. An eco-friendly and effective flame retardant coating for cotton fabric based on phytic acid doped silica sol approach. Prog. Org. Coat. 2020, 141, 105539. [CrossRef]

49. Chang, L.; Kong, X.; Wang, F.; Wang, L.; Shen, J. Layer-by-layer assembly of poly(N-acryloyl$\mathrm{N}^{\prime}$-propylpiperazine) and poly(acrylic acid): Effect of $\mathrm{pH}$ and temperature. Thin Solid Film. 2008, 516, 2125-2129. [CrossRef]

50. Shiratori, S.S.; Rubner, M.F. pH-dependent thickness behavior of sequentially adsorbed layers of weak polyelectrolytes. Macromolecules 2000, 33, 4213-4219. [CrossRef]

51. Tan, H.L.; McMurdo, M.J.; Pan, G.Q.; Van Patten, P.G. Temperature dependence of polyelectrolyte multilayer assembly. Langmuir 2003, 19, 9311-9314. [CrossRef]

52. McAloney, R.A.; Sinyor, M.; Dudnik, V.; Goh, M.C. Atomic force microscopy studies of salt effects on polyelectrolyte multilayer film morphology. Langmuir 2001, 17, 6655-6663. [CrossRef]

53. Lourenço, J.M.C.; Ribeiro, P.A.; Botelho do Rego, A.M.; Raposo, M. Counterions in layer-by-layer films-Influence of the drying process. J. Colloid Interf. Sci. 2007, 313, 26-33. [CrossRef]

54. Fujita, S.; Shiratori, S. The optical properties of ultra-thin films fabricated by layer-by-layer adsorption process depending on dipping time. Thin Solid Film. 2006, 499, 54-60. [CrossRef]

55. Mermut, O.; Barrett, C.J. Effects of charge density and counterions on the assembly of polyelectrolyte multilayers. J. Phys. Chem. B 2003, 107, 2525-2530. [CrossRef]

56. Sui, Z.J.; Salloum, D.; Schlenoff, J.B. Effect of molecular weight on the construction of polyelectrolyte multilayers: Stripping versus sticking. Langmuir 2003, 19, 2491-2495. [CrossRef]

57. Stockton, W.B.; Rubner, M.F. Molecular-Level Processing of Conjugated Polymers. 4. Layer-by-Layer Manipulation of Polyaniline via Hydrogen-Bonding Interactions. Macromolecules 1997, 30, 2717-2725. [CrossRef]

58. Wang, L.Y.; Cui, S.X.; Wang, Z.Q.; Zhang, X.; Jiang, M.; Chi, L.; Fuchs, H. Multilayer assemblies of copolymer $\mathrm{PSOH}$ and PVP on the basis of hydrogen bonding. Langmuir 2000, 16, 10490-10494. [CrossRef]

59. Fang, M.M.; Kaschak, D.M.; Sutorik, A.C.; Mallouk, T.E. A mix and match ionic-covalent strategy for self-assembly of inorganic multilayer films. J. Am. Chem. Soc. 1997, 119, 12184-12191. [CrossRef]

60. Ichinose, I.; Kawakami, T.; Kunitake, T. Alternate molecular layers of metal oxides and hydroxyl polymers prepared by the surface sol-gel process. Adv. Mater. 1998, 10, 535-539. [CrossRef]

61. Serizawa, T.; Hamada, K.; Kitayama, T.; Katsukawa, K.; Hatada, K.; Akashi, M. Stepwise assembly of isotactic poly(methyl methacrylate) and syndiotactic poly(methacrylic acid) on a substrate. Langmuir 2000, 16, 7112-7115. [CrossRef]

62. Serizawa, T.; Yamashita, H.; Fujiwara, T.; Fujimoto, N.; Hatada, K.; Akashi, M. Stepwise assembly of enantiomeric poly(lactide)s on surfaces. Macromolecules 2001, 34, 1996-2001. [CrossRef] 
63. Shimazaki, Y.; Mitsuishi, M.; Ito, S.; Yamamoto, M. Preparation and characterization of the layer-by-layer deposited ultrathin film based on the charge-transfer interaction in organic solvents. Langmuir 1998, 14, 2768-2773. [CrossRef]

64. Lvov, Y.M.; Ariga, K.; Onda, M.; Ichinose, I.; Kunitake, T. Alternate assembly of ordered multilayers of $\mathrm{SiO}_{2}$ and other nanoparticles and polyions. Langmuir 1997, 13, 6195-6203. [CrossRef]

65. Kotov, N.A.; Dekany, I.; Fendler, J.H. Layer-by-layer self-assembly of polyelectrolyte-semiconductor nanoparticle composite films. J. Phys. Chem. 1995, 99, 13065-13069. [CrossRef]

66. Koo, H.Y.; Yi, D.K.; Yoo, S.J.; Kim, D.Y. A snowman-like array of colloidal dimers for antireflecting surfaces. Adv. Mater. 2004, 16, 274-277. [CrossRef]

67. Ariga, K.; Lvov, Y.; Onda, M.; Ichinose, I.; Toyoki, K. Alternately assembled ultrathin film of silica nanoparticles and linear polycations. Chem. Lett. 1997, 26, 125-128. [CrossRef]

68. Lvov, Y.; Ariga, K.; Ichinose, I.; Kunitake, T. Formation of ultrathin multilayer and hydrated gel from montmorillonite and linear polycations. Langmuir 1996, 12, 3038-3044. [CrossRef]

69. Mamedov, A.; Ostrander, J.; Aliev, F.; Kotov, N.A. Stratified assemblies of magnetite nanoparticles and montmorillonite prepared by the layer-by-layer assembly. Langmuir 2000, 16, 3941-3949. [CrossRef]

70. Zhou, Y.; Hu, N.; Zeng, Y.; Ruslin, J.F. Heme protein-clay films: Direct electrochemistry and electrochemical catalysis. Langmuir 2002, 18, 211-219. [CrossRef]

71. Decher, G.; Hong, J.D.; Schmitt, J. Buildup of ultrathin multilayer films by a self-assembly process: III. Consecutively alternating adsorption of anionic and cationic polyelectrolytes on charged surfaces. Thin Solid Film. 1992, 210, 831-835. [CrossRef]

72. Decher, G.; Lvov, Y.; Schmitt, J. Proof of multilayer structural organization in self-assembled polycation-polyanion molecular films. Thin Solid Film. 1994, 244, 772-777. [CrossRef]

73. Korneev, D.; Lvov, Y.; Decher, G.; Schmitt, J.; Yaradaikin, S. Neutron reflectivity analysis of self-assembled film superlattices with alternate layers of deuterated and hydrogenated polysterenesulfonate and polyallylamine. Phys. B 1995, 213, 954-956. [CrossRef]

74. Laufer, G.; Carosio, F.; Martinez, R.; Camino, G.; Grunlan, J.C. Growth and fire resistance of colloidal silica-polyelectrolyte thin film assemblies. J. Colloid Interf. Sci. 2011, 356, 35669-35677. [CrossRef] [PubMed]

75. Alongi, J.; Carosio, F.; Frache, A.; Malucelli, G. Layer by layer coatings assembled through dipping, vertical or horizontal spray for cotton flame retardancy. Carbohydr. Polym. 2013, 92, 114-119. [CrossRef] [PubMed]

76. Carosio, F.; Di Blasio, A.; Cuttica, F.; Alongi, J.; Frache, A.; Malucelli, G. Flame retardancy of polyester fabrics treated by spray-assisted layer-by-layer silica architectures. Ind. Eng. Chem. Res. 2013, 52, 9544-9550. [CrossRef]

77. Uğur, S.S.; Sarışık, M.; Aktaş, A.H. Nano- $\mathrm{Al}_{2} \mathrm{O}_{3}$ multilayer film deposition on cotton fabrics by layer-by-layer deposition method. Mater. Res. Bull. 2011, 46, 1202-1206. [CrossRef]

78. Li, Y.C.; Mannen, S.; Schulz, J.; Grunlan, J.C. Growth and fire protection behavior of poss-based multilayer thin films. J. Mater. Chem. 2011, 21, 3060-3069. [CrossRef]

79. Li, Y.C.; Mannen, S.; Morgan, A.B.; Chang, S.; Yang, Y.H.; Condon, B.; Grunlan, J.C. Intumescent all-polymer multilayer nanocoating capable of extinguishing flame on fabric. Adv. Mater. 2011, 23, 3926-3930. [CrossRef] [PubMed]

80. Carosio, F.; Alongi, J.; Malucelli, G. Layer by Layer ammonium polyphosphate-based coatings for flame retardancy of polyester-cotton blends. Carbohydr. Polym. 2012, 88, 1460-1469. [CrossRef]

81. Laufer, G.; Kirkland, C.; Morgan, A.; Grunlan, J.C. Intumescent multilayer nanocoating, made with renewable polyelectrolytes, for flame-retardant cotton. Biomacromolecules 2012, 13, 2843-2848. [CrossRef] [PubMed]

82. Carosio, F.; Di Blasio, A.; Alongi, J.; Malucelli, G. Green DNA-based flame retardant coatings assembled through layer by layer. Polymer 2013, 54, 5148-5153. [CrossRef]

83. Alongi, J.; Di Blasio, A.; Milnes, J.; Malucelli, G.; Bourbigot, S.; Kandola, B.; Camino, G. Thermal degradation of DNA, an all-in-one natural intumescent flame retardant. Polym. Degrad. Stab. 2015, 113, 110-118. [CrossRef]

84. Alongi, J.; Carletto, R.A.; Di Blasio, A.; Carosio, F.; Bosco, F.; Malucelli, G. DNA: A novel, green, natural flame retardant and suppressant for cotton. J. Mater. Chem. A 2013, 1, 4779-4785. [CrossRef]

85. Pan, H.; Wang, W.; Pan, Y.; Song, L.; Hu, Y.; Liew, K.M. Formation of self-extinguishing flame retardant biobased coating on cotton fabrics via Layer-by-Layer assembly of chitin derivatives. Carbohydr. Polym. 2015, 115, 516-524. [CrossRef] 
86. Pan, Y.; Liu, L.; Zhang, Y.; Hu, Y.; Jiang, S.; Zhao, H. Effect of genipin crosslinked layer-by-layer self-assembled coating on the thermal stability, flammability and wash durability of cotton fabric. Carbohydr. Polym. 2019, 206, 396-402. [CrossRef]

87. Huang, G.; Liang, H.; Wang, X.; Gao, J. Poly (acrylic acid)/clay thin films assembled by layer-by-layer deposition for improving the flame retardancy properties of cotton. Ind. Eng. Chem. Res. 2012, 51, 12299-12309. [CrossRef]

88. Lin, D.; Zeng, X.; Li, H.; Lai, X. Facile fabrication of superhydrophobic and flame-retardant coatings on cotton fabrics via layer-by-layer assembly. Cellulose 2018, 25, 3135-3149. [CrossRef]

89. Wang, W.; Wang, X.; Pan, Y.; Liew, K.M.; Mohamed, O.A.; Song, L.; Hu, Y. Synthesis of phosphorylated graphene oxide based multilayer coating: Self-assembly method and application for improving the fire safety of cotton fabrics. Ind. Eng. Chem. Res. 2017, 56, 6664-6670. [CrossRef]

90. Li, S.; Ding, F.; Lin, X.; Li, Z.; Ren, X. Layer-by-layer self-assembly of organic-inorganic hybrid intumescent flame retardant on cotton fabrics. Fiber. Polym. 2019, 20, 538-544. [CrossRef]

91. Zhang, Y.; Tian, W.; Liu, L. Eco-friendly flame retardant and electromagnetic interference shielding cotton fabrics with multi-layered coatings. Chem. Eng. J. 2019, 372, 1077-1090. [CrossRef]

92. Li, S.; Lin, X.; Li, Z.; Ren, X. Hybrid organic-inorganic hydrophobic and intumescent flame-retardant coating for cotton fabrics. Compos. Commun. 2019, 14, 15-20. [CrossRef]

93. Chang, S.; Slopek, R.P.; Condon, B.; Grunlan, J.C. Surface coating for flame-retardant behavior of cotton fabric using a continuous layer-by-layer process. Ind. Eng. Chem. Res. 2014, 53, 3805-3812. [CrossRef]

94. Alongi, J.; Di Blasio, A.; Carosio, F.; Malucelli, G. UV-cured hybrid organic-inorganic Layer by Layer assemblies: Effect on the flame retardancy of polycarbonate films. Polym. Degrad. Stab. 2014, 107, 74-81. [CrossRef]

95. Carosio, F.; Alongi, J. Few durable layers suppress cotton combustion due to the joint combination of layer by layer assembly and UV-curing. RSC Adv. 2015, 5, 71482-71490. [CrossRef]

(C) 2020 by the author. Licensee MDPI, Basel, Switzerland. This article is an open access article distributed under the terms and conditions of the Creative Commons Attribution (CC BY) license (http://creativecommons.org/licenses/by/4.0/). 